\title{
165 rRNA gene sequences of ' Candidatus Campylobacter hominis', a novel uncultivated species, are found in the gastrointestinal tract of healthy humans
}

\author{
Andrew J. Lawson, Dennis Linton and John Stanley \\ Author for correspondence: John Stanley. Tel: +44181200 4400. Fax: +441812001569. \\ e-mail: ajlawson@hgmp.mrc.ac.uk
}

Molecular Biology Unit, Virus Reference Division, Central Public Health Laboratory, 61 Colindale Avenue, London NW9 5HT, UK

\begin{abstract}
Although some Campylobacter species are agents of gastroenteritis and periodontal disease in humans, little is known of the variety of campylobacters in the gastrointestinal tract of healthy individuals. This paper provides evidence for the existence of a previously undescribed, uncultivated Campylobacter species that may be a commensal in the healthy human gut. Saliva and faeces from 20 healthy individuals were examined by PCR assays specific for nine species of campylobacter (C. sputorum, C. concisus, C. upsaliensis, C. helveticus, C. lari, C. fetus, C. hyointestinalis, C. jejuni and C. coli) and for the genus as a whole. Genus-specific amplicons were produced from 19 of 20 saliva samples and from 18 of 20 faecal samples. C. concisus species-specific amplicons were produced from 19 of 20 saliva samples and 3 of $\mathbf{2 0}$ faecal samples. The faecal samples were all PCR-negative for other Campylobacter species. Three unidentified 16S rRNA Campylobacter genusspecific amplicons of faecal origin were sequenced. Phylogenetic analysis showed that these sequences were $99 \%$ similar, and clustered within the genus as a novel group which was termed HS (HS = healthy subject). A PCR primer pair specific for the HS group was designed from the sequence data and used to reexamine the original samples. Although it was not possible to culture the organism from faeces, specific PCR assay detected it in $\mathbf{1 0}$ of the 20 faecal samples, but not in any corresponding saliva samples. The authors propose that the source of the amplicons is a previously undescribed and so far uncultivated species, which they term 'Candidatus Campylobacter hominis'.
\end{abstract}

Keywords: Campylobacter, 16S rRNA sequences, human gastrointestinal tract

\section{INTRODUCTION}

The genus Campylobacter was proposed by Sebald $\&$ Veron (1963) to accommodate species previously regarded as microaerophilic vibrios. These organisms had long been recognized as a cause of illness and abortion in animals. Their significance in human gastroenteritis was not appreciated until techniques for isolating them from faeces were developed in the 1970s. C. jejuni is now the most frequently attributed cause of human gastroen-

The GenBank accession numbers for the sequences reported in this paper are AF062490 (HS-A), AF062491 (HS-B) and AF062492 (HS-C). teritis (Tauxe, 1992). Campylobacters occupy a variety of niches in a variety of hosts: C. jejuni and C. coli colonize poultry, pigs and cattle, and cause gastroenteritis in humans. C. hyointestinalis is associated with disease in pigs but has only rarely been isolated from humans. C. concisus, C. curvus and C. showae are commonly isolated from the human gingival crevice; but while sometimes associated with periodontal disease they are not considered to cause gastroenteritis (Skirrow, 1994).

Taxonomic studies of campylobacters have been hampered by the lack of distinctive phenotypic features within the group (Goossens \& Butzler, 1992). 23S rRNA gene hybridization studies by Vandamme et al. (1991) 
demonstrated distinct clusters within rRNA superfamily VI corresponding to three genera: Campylobacter, Helicobacter and Arcobacter. The same divisions were apparent in earlier studies of $16 \mathrm{~S}$ rRNA gene sequences (Paster \& Dewhirst, 1988; Thompson et al., 1988). PCR amplification of the $16 \mathrm{~S}$ rRNA gene, and subsequent phylogenetic analysis of the sequence data, have facilitated a new approach to the phylogenetic identification of this group of bacteria. Strategies based upon the PCR amplification of bacterial 16S rRNA genes have also been used to identify uncultivable bacteria, such as the agent of human ehrlichiosis (Anderson et al., 1991).

It has been estimated that approximately $40 \%$ of the bacterial forms observed during the microscopic examination of human faecal samples remain uncultured in the laboratory (Berg, 1996). Bearing in mind the fastidious growth requirements of campylobacters, and the sensitivity of certain Campylobacter species to antibiotics contained in selective media (Goossens \& Butzler 1992), in this study we used a $16 \mathrm{~S}$ rRNA PCRbased molecular approach to gain new insight into the incidence and identity of campylobacters in the gastrointestinal tract of healthy humans.

\section{METHODS}

Bacterial strains and culture conditions. The following Campylobacter, Helicobacter and Arcobacter strains were used as controls to test the specificity of PCR assays developed in the course of this study (ATCC, American Type Culture Collection; NCTC, National Collection of Type Cultures; RMIT, Royal Melbourne Institute of Technology; a superscript $\mathrm{T}$ denotes a type strain; ${ }^{*}$ denotes species cultivated anaerobically): C. coli NCTC $11366^{\mathrm{T}}$; C. concisus NCTC $11485^{\mathrm{T}}$; C. curvus* NCTC $11649^{\mathrm{T}}$; C. fetus subsp. fetus NCTC $10842^{\mathrm{T}}$; C. fetus subsp. venerealis NCTC $10354^{\mathrm{T}} ;$ C. gracilis $^{*}$ NCTC $12738^{\mathrm{T}}$; C. helveticus NCTC $12470^{\mathrm{T}}$; C. byoilei RMIT 32A; C. byointestinalis NCTC $11608^{\mathrm{T}}$; C. jejuni subsp. doylei NCTC $11951^{\mathrm{T}}$; C. jejuni subsp. jejuni NCTC $11351^{\mathrm{T}}$; C. lari NCTC $11352^{\mathrm{T}}$; C. mucosalis NCTC $11000^{\mathrm{T}}$; C. rectus* NCTC $11489^{\mathrm{T}}$; C. showae* NCTC $12843^{\mathrm{T}}$; C. sputorum subsp. bubulus NCTC $11367^{\mathrm{T}}$; C. sputorum subsp. faecalis NCTC $11415^{\mathrm{T}}$; C. sputorum subsp. sputorum NCTC $11528^{\mathrm{T}}$; C. upsaliensis NCTC $11541^{\mathrm{T}}$; [Bacteroides] ureolyticus* (species incertae sedis which is genotypically Campylobacter) NCTC $10941^{\mathrm{T}} ; H$. acinonychis NCTC $12686^{\mathrm{T}} ; H$. bilis ATCC $51630^{\mathrm{T}} ; H$. canis NCTC $12739^{\mathrm{T}} ; H$. cinaedi NCTC $12423^{\mathrm{T}}$; H. felis NCTC $12436^{\mathrm{T}}$; H. fennelliae NCTC $11612^{\mathrm{T}}$; $H$. hepaticus ATCC $51448^{\mathrm{T}}$; H. muridarum NCTC $12714^{\mathrm{T}}$; $H$. mustelae NCTC $12198^{\mathrm{T}} ; H$. nemestrinae NCTC $12491^{\mathrm{T}}$; H. pametensis ATCC $51478^{\mathrm{T}}$; H. pylori NCTC $11637^{\mathrm{T}}$; A. butzleri NCTC $12481^{\mathrm{T}}$; A. cryaerophilus NCTC $11885^{\mathrm{T}}$; A. nitrofigilis NCTC $12251^{\mathrm{T}}$; and A. skirrowii NCTC $12713^{\mathrm{T}}$.

All strains were cultured on Columbia blood agar plates. Microaerophilic species were incubated in an atmosphere of $5 \% \mathrm{O}_{2}, 5 \% \mathrm{CO}_{2}, 2 \% \mathrm{H}_{2}$ and $88 \% \mathrm{~N}_{2}$ (by vol.). Anaerobic species were incubated in an atmosphere of $5 \% \mathrm{CO}_{2}, 5 \% \mathrm{H}_{2}$ and $90 \% \mathrm{~N}_{2}$ (by vol.). All strains were grown at $37^{\circ} \mathrm{C}$ except A. nitrofigilis, which was grown at $25^{\circ} \mathrm{C}$.

Faecal samples. Faecal samples were collected from 20 human subjects ( 12 male, 8 female; age range 6 months to 45 years) with no current or recent gastrointestinal symptoms. They were diluted $1: 10$ in Brucella broth (Unipath) and vortexed briefly to produce a homogeneous suspension. Large particulate matter was allowed to settle out $(10 \mathrm{~min})$ and the supernatant was used for nucleic acid extraction and culture.

Saliva samples. Saliva samples were collected from the same subjects. Saliva samples rich in crevicular fluid were collected using a sponge swab, as described by Mortimer \& Parry (1994). Briefly, the sponge was rubbed firmly along the gum at the base of the teeth for about a minute, and the swab was then vortexed in a small volume of diluent in a close-fitting tube. The swab was then inverted and the tube centrifuged to collect the supernatant.

Nucleic acid extraction. Nucleic acid was extracted from a $100 \mu \mathrm{l}$ aliquot of homogenized faeces or saliva by the method of Boom et al. (1990), which employs guanidinium thiocyanate and diatomaceous silica for recovery of nucleic acid from cellrich sources. For the faecal samples only, this procedure was further modified by treatment with polyvinyl pyrrolidone to reduce the effect of substances inhibitory to PCR that might be co-extracted from faecal material (Lawson et al., 1997).

PCR analysis. All samples were examined using previously described PCR primers specific either for the genus Campylobacter or for individual species therein. The target genes were: the 16S rRNA gene of the five species C. upsaliensis, C. belveticus, C. lari, C. fetus, C. byointestinalis and the genus Campylobacter as a whole (Linton et al., 1996); a 16S rRNA gene sequence common to C. jejuni and C. coli (Linton et al., 1997); or the 23S rRNA genes of C. sputorum (Bastyns et al., 1994) and C. concisus (Bastyns et al., 1995). Samples were also examined with primer pairs designed in the course of this study (see below) by analysis of a database of published $16 \mathrm{~S}$ rRNA gene sequences from Campylobacter, Helicobacter and Arcobacter species and of amplicons sequenced in the course of the study.

PCR was carried out as follows: $2.5 \mu$ l of the nucleic acid sample was amplified (RoboCycler, Stratagene) in a $25 \mu \mathrm{l}$ reaction volume containing $20 \mathrm{mM}$ Tris/ $\mathrm{HCl}, \mathrm{pH} 8 \cdot 4 ; 50 \mathrm{mM}$ $\mathrm{KCl} ; 2.5 \mathrm{mM} \mathrm{MgCl}_{2} ; 0.625$ units Taq polymerase; $0.2 \mathrm{mM}$ of each deoxynucleotide; $0.4 \mu \mathrm{M}$ of each primer and an overlay of $25 \mu \mathrm{l}$ of mineral oil. Cycling conditions were as for published primers (Linton et al., 1996, 1997; Bastyns et al., 1994, 1995). Conditions for primer pairs first described in this report (CG12F/CG1507R and HS129F/HS1485R; see below) were: denaturation temperature $94^{\circ} \mathrm{C}$ for $1 \mathrm{~min}$; annealing temperature $60^{\circ} \mathrm{C}$ for $1 \mathrm{~min}$; extension temperature $72{ }^{\circ} \mathrm{C}$ for $1 \mathrm{~min} ; 30$ cycles. For each PCR a $10 \mu \mathrm{l}$ aliquot of the reaction was analysed by electrophoresis in a $1 \%(\mathrm{w} / \mathrm{v})$ agarose gel.

Campylobacter culture. All faecal samples were examined for the presence of Campylobacter species by culture on modified charcoal cefoperazone deoxycholate agar (CCDA, Unipath) and by the membrane filter method of Steele \& McDermott (1984). Inoculated plates were incubated for up to $7 \mathrm{~d}$ at $37^{\circ} \mathrm{C}$ under microaerobic conditions.

Sequencing of PCR amplicons. Newly described primers for the genus Campylobacter (see below) were used to generate a $1450 \mathrm{bp}$ amplicon suitable for sequence analysis. Both strands of the products amplified from faecal DNA extracts were sequenced as described by Embley (1991) using an ABI PRISM dye terminator cycle sequencing kit according to the manufacturer's instructions. The data were used as input for the CHECK_CHIMERA program of the Ribosomal Database Project (Maidak et al., 1997) to determine any likelihood that the amplified sequences were of chimaeric origin. 


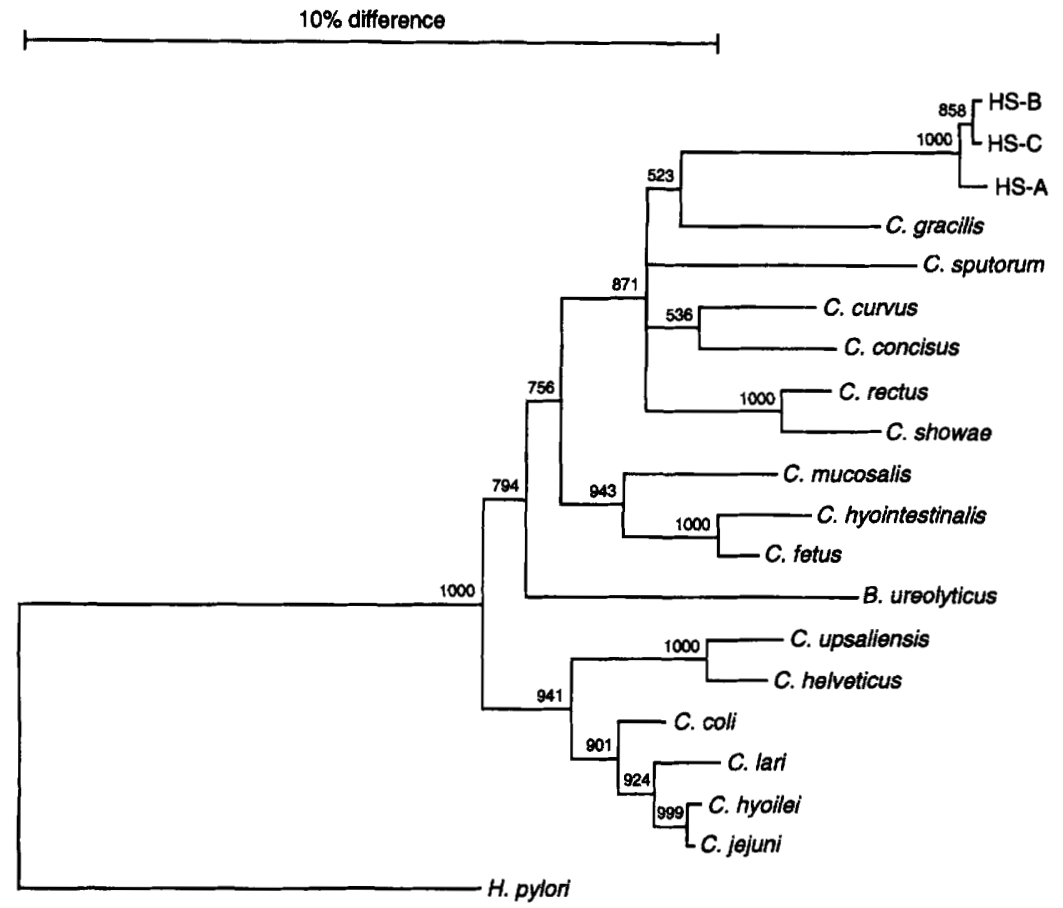

\begin{abstract}
Fig. 1. Neighbour-joining tree showing phylogenetic relationships of the 165 rDNA sequences HS-A, HS-B and HS-C ('Candidatus C. hominis'), within the genus Campylobacter. Numbers at branch points indicate bootstrap analysis values performed with 1000 resampled data sets.
\end{abstract}

Signature nucleotide analysis and secondary structure prediction. Sequences were aligned with $16 \mathrm{~S}$ rDNA gene sequences representative of the five subclasses $(\alpha, \beta, \gamma, \delta$ and $\varepsilon)$ of the Proteobacteria. Signature nucleotide positions were identified as previously described (Woese, 1987; Rainey et al., 1993; Haddad et al., 1995). A secondary-structure model of the sequence of the PCR-generated amplicon was constructed, based on a model of the $16 \mathrm{~S}$ rRNA secondary structure of $C$. sputorum subsp. sputorum. This was retrieved as a PostScript file from the Ribosomal Database Project (Maidak et al., 1997).

Phylogenetic analysis. For phylogenetic analysis, sequences were aligned with the $16 \mathrm{~S}$ rDNA sequences of Helicobacter pylori, [Bacteroides] ureolyticus and 15 species of Campylobacter using the Multalin program (Corpet, 1988). When regions of uncertain alignment had been removed, the data were used as input for phylogenetic analysis, using the neighbour-joining method (Saitou \& Nei, 1987) as implemented in the TREeCON package (Van de Peer \& De Wachter, 1993). Data were corrected for multiple base changes using the method of Jukes \& Cantor (1969), and bootstrap analysis was performed with 1000 resampled data sets. The H. pylori sequence was used to root the tree. A sequence dissimilarity matrix was constructed between novel sequences and between them and the reference species/strains above.

\section{RESULTS}

\section{PCR detection of Campylobacter in human faecal samples}

Eighteen of the 20 faecal samples yielded an amplicon with the Campylobacter genus-specific primers. Three of these faecal samples were also positive by PCR assay for the 23S rRNA gene of $C$. concisus. PCR assays for the $16 \mathrm{~S}$ rRNA genes of C. upsaliensis, C. helveticus, $C$. lari, C. fetus, C. hyointestinalis, C. jejuni, C. coli, and the $23 \mathrm{~S}$ rRNA gene of C. sputorum, were negative for all 20 faecal samples.

\section{Analysis of genus amplicons from faeces}

A new set of Campylobacter genus-specific primers were designed for production of a $1495 \mathrm{bp}$ amplicon for phylogenetic (sequence) analysis. The forward primer (CG12F) was 5'-TTG ATC CTG GCT CAG AGT (nucleotides 12-29) and the reverse primer (CG1507R) was 5'-TTC ACC CCA GTC GCT GAT (nucleotides 1507-1490). The reference strains of all Campylobacter species yielded the expected $1495 \mathrm{bp}$ amplicon with these primers. The reference strains of Helicobacter and Arcobacter species were all negative.

The 18 samples previously positive for the Campylobacter genus all yielded 1495 bp amplicons with the CG12F/CG1507R primer pair. Three such amplicons, from samples negative in the $C$. concisus assay, were sequenced and compared with our database of known $16 \mathrm{~S}$ rRNA sequences. These three sequences were readily aligned within the genus Campylobacter, and were more than $99 \%$ similar to each other. They were termed HS (healthy subject) sequences: HS-A, HS-B and HS-C. A neighbour-joining tree was derived from phylogenetic analysis (Fig. 1): this shows the new sequences clustering together within Campylobacter, but distinct from previously described species. The sequences were analysed with the CHECK_CHIMERA program, which excluded a chimaeric origin. The integrity of the product was confirmed by analysis of the secondary structure of the HS-A rRNA (Fig. 2).

The percentage dissimilarity between the HS sequences ranged from $0.2 \%$ between HS-A and HS-B to $0.7 \%$ between HS-A and HS-C. Dissimilarities between HS-A 


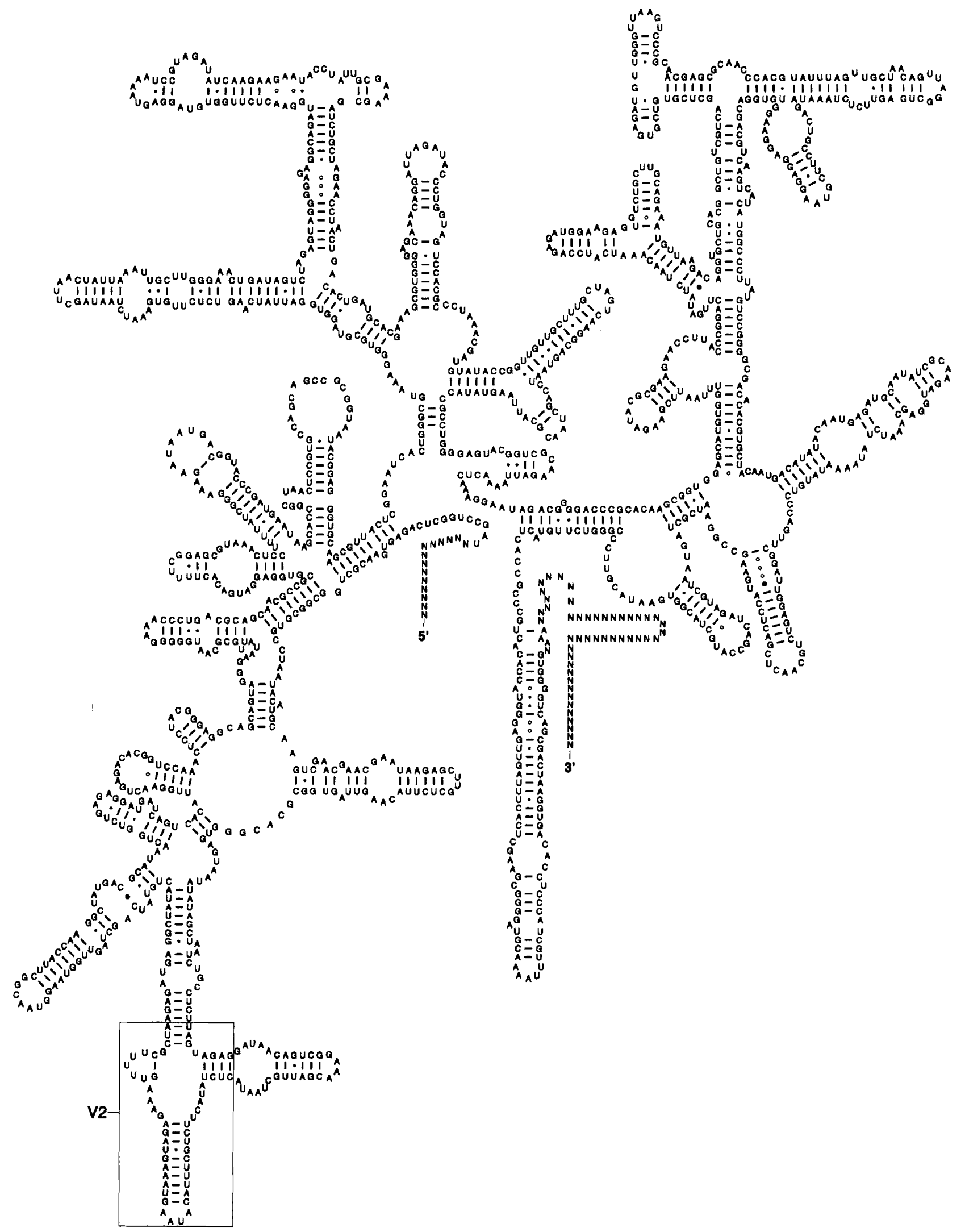

Fig. 2. Proposed 16S rRNA secondary structure of sequence HS-A ('Candidatus C. hominis'), based on a model of that of C. sputorum subsp. sputorum, retrieved from the Ribosomal Database Project (Maidak et al., 1997). The V2 region is boxed (cf. Fig. 3). 
and the most closely related known species were as follows: C. gracilis $6.6 \%$, C. rectus $7 \cdot 2 \%$, C. concisus $7 \cdot 3 \%, C$. curvus $7.5 \%$ and C. showae $7 \cdot 7 \%$. The percentage dissimilarity between HS-A and C. jejuni was $10 \cdot 1 \%$ and between HS-A and $H$. pylori it was $17 \cdot 6 \%$.

We analysed the signature base positions typical for the $\varepsilon$ subdivision of the Proteobacteria (to which the genus Campylobacter belongs). Ninety-five per cent of these bases were present in the HS-A sequence (Table 1). In addition, we compared the secondary structure of the V2 region of the $16 \mathrm{~S}$ rRNA molecule (boxed area of Fig. 2) with known conformations of this region (Fig. 3). The V2 region was characteristic of the Campylobacter subgroup within the $\varepsilon$ subdivision, and was distinct from that of the Helicobacter subgroup (Lane et al., 1992).

\section{HS sequence-specific PCR assay}

A PCR specific for the HS sequences was designed. The forward primer HS129F (nucleotides 129-149) was 5'GCT AAT CTG CCT CTT AGT AGA and the reverse primer HS1485R (nucleotides 1485-1465) was 5'-CTG TGG AGG GTA GCA AAT TTT. The predicted HS amplicon size was $1356 \mathrm{bp}$. The reference strains of Campylobacter, Helicobacter and Arcobacter all failed to yield an amplicon with these primers. However, 10 of the 20 faecal samples previously examined, including the three that yielded the HS-A, B and C sequences, gave an amplicon of the predicted size with primer pair HS129F/HS1485R.

\section{Campylobacter culture from faeces}

One of the 20 faecal samples produced colonies of C. concisus following culture by the membrane-filter method. This sample was also positive for C. concisus by PCR assay. No other Campylobacter species were isolated by membrane-filter or CCDA culture.

Follow-up faecal samples were obtained from individuals PCR-positive for the HS sequence. Further attempts to isolate Campylobacter species by the membrane-filter method were made. Filtrates were cultured on Columbia blood agar and fastidious anaerobe agar plates (Unipath) incubated at 25,37 and $42{ }^{\circ} \mathrm{C}$, in both microaerobic and anaerobic atmospheres. No Campylobacter colonies were seen after $7 \mathrm{~d}$ incubation under microaerobic conditions. Under anaerobic conditions, a mixed growth of bacteria was obtained, but neither individual colonies nor sweeps of the plate(s) yielded PCR-positives (Campylobacter genus-specific or HS sequence-specific assays).

\section{PCR assay of saliva samples}

Nineteen of the 20 saliva samples from the individuals studied produced amplicons with Campylobacter genusspecific primers (Table 2). These same 19 samples also yielded amplicons with the $23 \mathrm{~S}$ rRNA C. concisusspecific primers. All samples were PCR-negative for
C. upsaliensis, C. helveticus, C. lari, C. fetus, C. hyointestinalis, C. jejuni, C. coli and C. sputorum. They were all negative for the HS sequence.

\section{DISCUSSION}

Uncultured micro-organisms associated with certain pathological processes have previously been characterized by analysis of $16 \mathrm{~S}$ rRNA gene sequences. For example in Whipple's disease, monomorphic bacilli were observed in pathological tissues, but all attempts to culture them failed, until their recent propagation in cell culture (Schoedon et al., 1997). Nonetheless, amplification of prokaryotic $16 \mathrm{~S}$ rRNA from infected eukaryotic host tissue, and subsequent sequence analysis of the amplicon, had allowed the taxonomic position of the bacilli, now named Tropheryma whippelii, to be deduced (Relman et al., 1992). In a similar manner, 'Gastrospirillum hominis', a culture-resistant bacterium observed in histological samples from the human gastric mucosa, was identified as a Helicobacter and provisionally named ' $H$. heilmanii' (Solnick et al., 1993). A bacterium which resembles ' $H$. heilmanni' has subsequently been cultured (Anderson et al., 1996), though as yet it has not been confirmed that the organisms are the same.

In the pathological conditions mentioned above, a microbial aetiology based on microscopic observation of histological tissue sections had already been established. PCR amplification and sequence analysis of prokaryotic $16 \mathrm{~S}$ rRNA genes from infected eukaryotic tissue, which was relatively free of other bacteria, then established the species identity of the infective agent. By contrast, in the analysis of complex bacterial communities such as dental plaque (Wilson et al., 1997), molecular identification of the uncultured bacterial components has been made possible by representative cloning of prokaryotic $16 \mathrm{~S}$ rRNA amplicons, followed by sequence analysis. It has been recommended that taxa identified in this manner be accorded provisional status (Candidatus) as incompletely described prokaryotes (Murray \& Schleifer, 1994; Murray \& Stackebrandt, 1995). The experiments described in the present report represent a distinct approach to the molecular ecology of complex communities. We have employed the specificity of PCR primer design at the level of a bacterial genus to selectively amplify target genes from a microbial ecosystem, in this case Campylobacter genes from faeces of healthy humans. The same approach might have diverse applications in the investigation of the molecular ecology of enteric disease. This is particulary relevant to the genus Campylobacter, which has relatively fastidious growth requirements and is thought to have viable but non-culturable states (Jones et al., 1991).

The human gastrointestinal tract has been estimated to contain approximately $10^{\mathbf{1 4}}$ bacteria, belonging to many species. These occupy a progressively changing microbial habitat from the oral cavity through the stomach and small bowel to the large bowel (Berg, 1996). Several 
Table 1. Comparison of sequence base positions for the five subclasses of the Proteobacteria and the HS-A sequence

Information for the $\alpha$ to $\delta$ subdivisions is from Rainey et al. (1993) and for the $\varepsilon$ subdivision from Haddad et al. (1995). The consensus composition from the other eubacterial phyla (column 8 ) is from Rainey et al. (1993). Major bases are shown in upper case; if no other base is specified, the base shown accounts for $>90 \%$ of cases. Minor bases (present in $<15 \%$ of cases) are shown in lower case. Y, pyrimidine; R, purine; N, any nucleotide. -, Position not present; ND, sequence not determined.

\begin{tabular}{|c|c|c|c|c|c|c|c|}
\hline Position & $\alpha$ & $\boldsymbol{\beta}$ & $\gamma$ & $\delta$ & $\varepsilon$ & HS-A & Other \\
\hline 6 & $\mathrm{U}$ & $\mathrm{R}: \mathrm{u}$ & G & G & G & ND & G \\
\hline 7 & G & $A: U$ & A & G & G & ND & G \\
\hline 44 & A & A & A & G & G & G & G \\
\hline 50 & A & $\mathrm{U}$ & A & A & A & A & A \\
\hline 107 & $A: G$ & G & G & G & G & G & $\mathrm{N}$ \\
\hline 108 & G:c:a & A & G: $\mathbf{a}$ & C & $\mathrm{C}: \mathrm{u}$ & C & G:C \\
\hline 124 & G & A & $\mathrm{N}$ & G & A & A & G \\
\hline 129 & $A: c$ & A & $A: g$ & U & $\mathrm{U}$ & U & $\mathrm{U}$ \\
\hline 129.1 & - & - & - & A & A & A & A \\
\hline 233 & $\mathrm{C}$ & $\mathrm{C}$ & C & Y & $C: R: u$ & G & C \\
\hline 236 & G & $\mathrm{A}$ & $A: g$ & G & A & $\mathrm{A}$ & $\mathrm{G}$ \\
\hline 237 & C & $\mathrm{U}$ & $\mathrm{N}$ & C & $\mathrm{U}$ & $\mathrm{U}$ & C \\
\hline 242 & G & $\mathrm{G}$ & $\mathrm{G}$ & C:g & $\mathrm{U}: \mathrm{c}$ & U & $\mathrm{Y}$ \\
\hline 284 & C & C & C & $G: c$ & $G: \mathbf{a}$ & U & $\mathrm{Y}$ \\
\hline 370 & G & G & $C: G$ & C & C & C & G:C \\
\hline 371 & $A: g$ & A & A & $G: a$ & U:g:a & G & $\mathrm{N}$ \\
\hline 390 & U:c & $\mathrm{U}$ & $\mathrm{U}$ & $\mathrm{C}: \mathrm{u}$ & $A: c: u$ & C & $\mathrm{Y}$ \\
\hline 391 & C & C & $\mathrm{G}: \mathrm{C}$ & G & G & G & G:C \\
\hline 398 & $\mathrm{U}$ & $\mathrm{U}$ & $\mathrm{U}$ & C & C & C & $\mathrm{C}$ \\
\hline 438 & $\mathrm{U}$ & $\mathrm{U}$ & $\mathrm{U}$ & G:u & $\mathrm{U}$ & $\mathrm{U}$ & $\mathrm{G}: \mathrm{U}$ \\
\hline 449 & $A: C$ & $A: C$ & $\mathrm{R}$ & A & A & A & A \\
\hline 485 & $\mathrm{G}: \mathrm{u}$ & G & $\mathrm{U}$ & G & G & G & G \\
\hline 496 & A & A & A & $G: a$ & A & A & $\mathrm{R}$ \\
\hline 502 & C & A & A & $A: g$ & $A: u$ & A & C \\
\hline 513 & $\mathrm{U}: \mathrm{C}$ & A & C & C & $\mathrm{C}$ & C & $A: C$ \\
\hline 538 & $A: c$ & $\mathrm{U}$ & G & G & G & G & $\mathrm{U}: \mathrm{G}: \mathrm{A}$ \\
\hline 543 & G & $\mathrm{U}$ & $\mathrm{U}$ & U:c & $\mathrm{U}$ & $\mathrm{U}$ & G \\
\hline 554 & $\mathrm{Y}$ & A & A & $\mathrm{U}: \mathrm{a}$ & C & C & $\mathrm{U}$ \\
\hline 564 & C & C & C & $U: c$ & C & C & $\mathrm{Y}$ \\
\hline 640 & $\mathrm{~A}$ & $\mathrm{U}: \mathrm{G}: \mathrm{a}$ & A & A & A & A & A \\
\hline 689 & A & C & C & $\mathrm{R}: \mathrm{u}$ & G & G & $\mathrm{C}$ \\
\hline 690 & G & A & G & G: $a$ & $\bar{G}$ & A & G \\
\hline 698 & $\mathrm{U}$ & G & G & $Y: a$ & C & $\mathrm{C}$ & G \\
\hline 722 & G & A & G:a & $G: a$ & A & A & G \\
\hline 760 & $G: u$ & $\mathrm{U}: \mathrm{g}$ & G & G & $\mathrm{U}: \mathrm{g}$ & $\mathrm{U}$ & G \\
\hline 812 & G & C & G & G & C & C & G \\
\hline 822 & $\mathrm{R}: \mathrm{u}$ & $\mathrm{U}$ & $\mathrm{U}$ & $\mathrm{R}: \mathrm{u}$ & $A: U: g: c$ & $\mathrm{U}$ & $\mathrm{Y}: \mathrm{A}$ \\
\hline 823 & $\mathrm{R}$ & C & C & $\mathrm{R}: \mathrm{u}$ & A & A & $\mathbf{R}$ \\
\hline 825 & G & A & A & $A: g$ & $\mathbf{R}$ & A & $\mathbf{R}$ \\
\hline 871 & $\mathrm{U}$ & G & $\mathrm{U}$ & $\mathrm{U}$ & $\mathrm{U}$ & $\mathrm{U}$ & $\mathrm{U}$ \\
\hline 875 & C & $\mathrm{U}$ & $\mathrm{U}$ & $\mathrm{U}: \mathrm{c}$ & $\mathrm{Y}$ & $\mathrm{U}$ & $\mathrm{Y}$ \\
\hline 877 & $\mathrm{Y}$ & G & $\mathrm{G}$ & $Y: a$ & $\mathrm{U}$ & $\mathrm{U}$ & $\mathrm{Y}$ \\
\hline 878 & $Y: a$ & A & A & $Y: a$ & $A: U: c: g$ & A & $\mathrm{R}: \mathrm{U}$ \\
\hline 916 & G & G & $\mathrm{U}: \mathrm{G}$ & G & G & G & G \\
\hline 929 & G & A & G & G & A & A & G \\
\hline 947 & G & U & G & G:u & G & G & G \\
\hline 948 & G & $\mathrm{G}: \mathrm{U}$ & $\mathrm{C}: \mathrm{u}$ & $\mathrm{Y}$ & C & C & $\mathrm{C}$ \\
\hline
\end{tabular}


Table 1. (cont.)

\begin{tabular}{|c|c|c|c|c|c|c|c|}
\hline Position & $\alpha$ & $\beta$ & $\gamma$ & $\delta$ & $\varepsilon$ & HS-A & Other \\
\hline 976 & G & $A: g$ & G & G & $\mathrm{G}: \mathrm{a}$ & G & G \\
\hline 1015 & G & G & G & $A: g$ & $\mathbf{R}$ & $\mathrm{U}$ & $\mathrm{R}$ \\
\hline 1024 & $\mathrm{Y}$ & G & G & G:c & G & G & $\mathrm{N}$ \\
\hline 1026 & $\mathrm{U}$ & G & G & G & $\mathrm{G}: \mathrm{u}$ & $\mathrm{U}$ & $\mathrm{N}$ \\
\hline 1116 & C & $\mathrm{U}$ & U & $\mathrm{Y}$ & C & C & U \\
\hline 1120 & $\mathrm{Y}$ & A & $\mathrm{C}$ & $Y: G$ & $\mathrm{Y}: \mathrm{A}$ & $\mathrm{U}$ & $\mathbf{N}$ \\
\hline 1153 & $\mathbf{R}$ & $\mathrm{U}$ & G:u & $\mathrm{N}$ & $\mathbf{R}: \mathrm{U}$ & A & $\mathrm{N}$ \\
\hline 1219 & $\mathrm{U}$ & A:g & $A: U$ & A & $\mathrm{R}$ & G & $\mathrm{R}: \mathrm{U}$ \\
\hline 1233 & G & $C: A$ & G & $\mathrm{R}$ & G & G & $\mathrm{G}$ \\
\hline 1234 & C & A & C & $C: a$ & C & C & C \\
\hline 1246 & $\mathrm{U}: \mathrm{c}$ & G & $\mathrm{R}$ & G:u & $\mathbf{R}$ & A & G \\
\hline 1252 & $\mathrm{U}$ & A & A & A & $A: U$ & U & $A: Y$ \\
\hline 1260 & $G: Y$ & C & G:u & $G: Y$ & $A: g$ & A & G \\
\hline 1291 & $\mathbf{R}$ & C & Y & C:g & $\mathrm{Y}$ & U & C \\
\hline 1297 & $\mathrm{U}$ & G & G & $Y^{\circ}$ & Y & C & $\mathrm{U}$ \\
\hline 1298 & C & $\mathrm{U}$ & U & C:A & C & C & C \\
\hline 1325 & G & C:g & C & $\mathrm{C}$ & $C: g$ & C & C \\
\hline 1421 & U & G & G:U & Y & $\mathrm{U}$ & $\mathrm{U}$ & $\mathrm{U}$ \\
\hline 1426 & Y & $Y: a$ & G & $\mathrm{U}: \mathrm{R}$ & $\mathrm{U}$ & $\mathrm{U}$ & A \\
\hline 1431 & Y & A & A & $Y: a$ & Y & C & $\mathrm{Y}$ \\
\hline 1437 & $Y: a$ & A & A & C & $C: g: a$ & G & C \\
\hline 1441 & G:u:a & A & A & G:u & A & A & $\mathrm{N}$ \\
\hline 1443 & G & C:u:g & $\mathrm{Y}$ & G & $\mathrm{R}$ & G & G:C \\
\hline 1460 & A & $\mathrm{C}$ & $\mathrm{C}$ & A & $\mathrm{A}: \mathrm{u}$ & $\mathrm{U}$ & A \\
\hline 1464 & $\mathrm{R}$ & U & $\mathrm{U}$ & G & G:u & G & G \\
\hline 1467 & C & C & $C: \mathbf{a}$ & Y & $\mathrm{C}$ & $\mathrm{C}$ & G \\
\hline 1469 & C & C & C & $A: u: c$ & $\mathrm{R}$ & C & $\mathrm{R}$ \\
\hline 1481 & C:g & $\mathrm{U}$ & $\mathrm{U}$ & $\mathrm{U}: \mathrm{c}$ & G & C & U \\
\hline
\end{tabular}

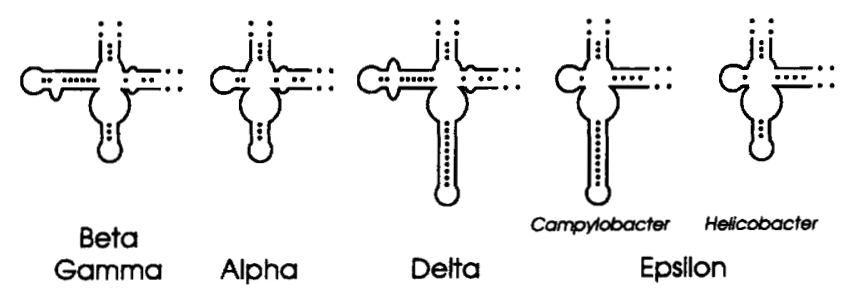

Fig. 3. Secondary structures of the V2 region of 16S rRNA for the five subdivisions of the Proteobacteria, adapted from Lane et al. (1992). Differences in the structures formed by Campylobacter and Helicobacter are indicated.

Campylobacter species are associated with the periodontal niche within the oral cavity, notably C. concisus, C. gracilis, C. rectus (Tanner et al., 1981) and C. showae (Etoh et al., 1993). However, little is known of the role of Campylobacter species as components of the microflora of the lower gastrointestinal tract of healthy humans. Our study indicates that $16 \mathrm{~S}$ rRNA sequences originating from a previously undescribed and presently non-cultivable Campylobacter species are to be found in faecal material from half of the healthy humans studied, irrespective of age or sex. We have therefore termed this provisional species 'Candidatus Campylobacter hominis' (L. gen. n. hominis of man, host where first isolated).

Eighteen of the 20 faecal samples examined produced Campylobacter genus-specific amplicons, but with published species-specific PCR assays (for 9 of the 14 species) only three yielded amplicons (for C. concisus). Sequencing of three of the genus amplicons (non-C. concisus) revealed that they originated from a novel species, 'Candidatus C. hominis'. Specific primers designed from these sequences showed that this novel species was present in 10 of 20 of the faecal samples. In 12 of 18 genus-positive faecal samples we could account for the genus signal by species-specific PCR (nine contained 'Candidatus $\mathrm{C}$. hominis', two contained C. concisus and one contained both species), and in six samples we could not. This might reflect a difference in sensitivity between the genus- and species-specific PCRs. Alternatively, these genus amplicons might have originated from Campylobacter species for which PCR assays are not presently available, such as $C$. showae or $C$. gracilis.

In contrast to the faecal samples, saliva samples from the same donors showed 19 of 20 to be PCR positive for the genus Campylobacter and for C. concisus but PCRnegative for 'Candidatus C. hominis' (Table 2). This 
Table 2. Comparative PCR assay of faecal and saliva samples

\begin{tabular}{|c|c|c|c|c|c|c|}
\hline \multirow{2}{*}{$\begin{array}{l}\text { Sample } \\
\text { no. }\end{array}$} & \multicolumn{3}{|c|}{ PCR from faeces } & \multicolumn{3}{|c|}{ PCR from saliva } \\
\hline & $\begin{array}{c}\text { Campylobacter } \\
\text { genus }\end{array}$ & $\begin{array}{c}\text { C. } \\
\text { concisus }\end{array}$ & $\begin{array}{c}\text { 'C. } \\
\text { hominis' }\end{array}$ & $\begin{array}{c}\text { Campylobacter } \\
\text { genus }\end{array}$ & $\begin{array}{c}\text { C. } \\
\text { concisus }\end{array}$ & $\begin{array}{c}\text { 'C. } \\
\text { hominis' }\end{array}$ \\
\hline 1 & + & - & + & + & + & - \\
\hline 2 & + & - & + & + & + & - \\
\hline 3 & + & - & + & + & + & - \\
\hline 4 & + & - & + & + & + & - \\
\hline 5 & + & - & + & + & + & - \\
\hline 6 & + & - & - & - & - & - \\
\hline 7 & + & + & - & + & + & - \\
\hline 8 & + & - & + & + & + & - \\
\hline 9 & + & - & + & + & + & - \\
\hline 10 & + & - & - & + & + & - \\
\hline 11 & + & + & + & + & + & - \\
\hline 12 & - & - & - & + & + & - \\
\hline 13 & + & - & - & + & + & - \\
\hline 14 & + & - & - & + & + & - \\
\hline 15 & + & - & - & + & + & - \\
\hline 16 & + & - & - & + & + & - \\
\hline 17 & - & - & - & + & + & - \\
\hline 18 & + & - & + & + & + & - \\
\hline 19 & + & - & + & + & + & - \\
\hline 20 & + & + & - & + & + & - \\
\hline Total: & $18 / 20$ & $3 / 20$ & $10 / 20$ & $19 / 20$ & $19 / 20$ & $0 / 20$ \\
\hline$\%$ & 90 & 15 & 50 & 95 & 95 & 0 \\
\hline
\end{tabular}

leads us to conclude that 'Candidatus C. hominis' is an inhabitant of the gut rather than the oral cavity. $C$. concisus, from this small data set, appears as an oral cavity microbe $(95 \%$ carriage) which is present in the lower gastrointestinal tract less frequently $(15 \%$ carriage) and probably transiently.

The gastrointestinal tract microflora significantly influences the physiological and immunological functions of the host. A balanced community of indigenous bacteria inhibits pathogenic colonization, although in certain circumstances, indigenous bacteria may also be opportunistic pathogens (Berg, 1996). In this context, the presence of a previously undescribed, uncultivated Campylobacter in the gut of a large proportion of healthy individuals raises a number of questions. Does 'Candidatus C. hominis' occupy a purely commensal niche? Under certain circumstances, could it be involved in pathological processes, such as cases of gastroenteritis for which an aetiological agent is not established (Wilson et al., 1997)? If it is a commensal, does its carriage provide protective immunity, or resistance to colonization by pathogenic campylobacters such as $C$. jejuni and C. coli? Does its presence in the healthy gut have any implications for the future development of vaccines against campylobacter enteritis?

In the present study we have considered the variety of Campylobacter species within the gastrointestinal microflora of healthy humans and described sequences that represent a Campylobacter species which is probably widely distributed in the human population, including infants. We suggest that its role in health and disease deserves further investigation.

\section{ACKNOWLEDGEMENTS}

This work was partially supported by a grant from the Department of Health, London (DH220B). We thank R. J. Owen for useful discussion and those who donated samples for this study.

\section{REFERENCES}

Anderson, B. E., Dawson, J. E., Jones, D. C. \& Wilson, K. H. (1991). Ehrlichia chaffensis, a new species associated with human ehrlichiosis. J Clin Microbiol 29, 2838-2842.

Anderson, L. P., Norgaard, A., Holck, S., Blom, J. \& Elsborg, L. (1996). Isolation of a 'Helicobacter beilmanii'-like organism from the human stomach. Eur J Microbiol Infect Dis 15, 95-96.

Bastyns, K., Chapelle, S., Vandamme, P., Goossens, H. \& De Wachter, R. (1994). Species-specific detection of campylobacters important in veterinary medicine by PCR amplification of $23 \mathrm{~S}$ rDNA areas. Syst Appl Microbiol 17, 563-568.

Bastyns, K., Chapelle, S., Vandamme, P., Goossens, H. \& De Wachter, R. (1995). Specific detection of Campylobacter concisus by PCR amplification of $23 \mathrm{~S}$ rDNA areas. Mol Cell Probes 9, 247-250.

Berg, R. D. (1996). The indigenous gastrointestinal microflora. Trends Microbiol 4, 430-435. 
Boom, R., Sol, C. J. A., Salimans, M. M. M., Jansen, C. L., Wertheim van Dillen, P. M. E. \& van der Noordaa, J. (1990). Rapid and simple method for purification of nucleic acids. $J$ Clin Microbiol 28, 495-503.

Corpet, F. (1988). Multiple sequence alignment with hierarchical clustering. Nucleic Acids Res 16, 10881-10890.

Embley, T. M. (1991). The linear PCR reaction: a simple and robust method for sequencing amplified rRNA genes. Lett Appl Microbiol 13, 171-174.

Etoh, Y., Dewhirst, F. E., Paster, B. J., Yamamoto, A. \& Goto, N. (1993). Campylobacter showae sp. nov., isolated from the human oral cavity. Int J Syst Bacteriol 43, 631-639.

Goossens, H. \& Butzler, J. P. (1992). Isolation and identification of Campylobacter spp. In Campylobacter jejuni: Current Status and Future Trends, pp. 93-109. Edited by I. Nachamkin, M. J. Blaser $\&$ L.S. Tompkins. Washington, DC: American Society for Microbiology.

Haddad, A., Camacho, F., Durand, P. \& Cary, S. C. (1995). Phylogenetic characterisation of the epibiotic bacteria associated with the hydrothermal vent polychaete Alvinella pompejana. Appl Environ Microbiol 61, 1679-1687.

Jones, D. M., Sutcliffe, E. M. \& Curry, A. (1991). Recovery of viable but non-culturable Campylobacter jejuni. J Gen Microbiol 137, $2477-2482$.

Jukes, T. H. \& Cantor, C. R. (1969). Evolution of protein molecules. In Mammalian Protein Metabolism, pp. 21-132. Edited by H. N. Munro. New York: Academic Press.

Lane, D. J., Harrison, A. P., Stahl, D., Pace, B., Giovannoni, S. J., Olsen, G. J. \& Pace, N. R. (1992). Evolutionary relationships among sulfur- and iron-oxidizing eubacteria. J Bacteriol 174, 269-278.

Lawson, A. J., Linton, D., Stanley, J. \& Owen, R. J. (1997). Polymerase chain reaction detection and speciation of Campylobacter upsaliensis and C. helveticus in human faeces and comparison with culture techniques. J Appl Microbiol 83, 375-380.

Linton, D., Owen, R. J. \& Stanley, J. (1996). Rapid identification by PCR of the genus Campylobacter and of five Campylobacter species enteropathogenic for man and animals. Res Microbiol 147, 707-718.

Linton, D., Lawson, A. J., Owen, R. J. \& Stanley, J. (1997). PCR detection, identification to species level and fingerprinting of Campylobacter jejuni and Campylobacter coli direct from diarrheic samples. J Clin Microbiol 35, 2568-2572.

Maidak, B. L., Olsen, G. L., Larsen, N., Overbeek, R., McCaughey, M. J. \& Woese, C. R. (1997). The RDP (Ribosomal Database Project). Nucleic Acids Res 25, 109-111.

Mortimer, P. P. \& Parry, J. V. (1994). Detection of antibody to HIV in saliva: a brief review. Clin Diagn Virol 2, 231-242.

Murray, R. G. E. \& Schleifer, K. H. (1994). Taxonomic notes: a proposal for recording the properties of putative taxa of procaryotes. Int J Syst Bacteriol 44, 174-176.

Murray, R. G. E. \& Stackebrandt, E. (1995). Taxonomic note: implementation of the provisional status Candidatus for incompletely described procaryotes. Int J Syst Bacteriol 45, 186-187.

Paster, B. J. \& Dewhirst, F. E. (1988). Phylogeny of campylobacters, wolinellas, Bacteroides gracilis and Bacteroides ureolyticus by $16 \mathrm{~S}$ ribosomal ribonucleic acid sequencing. Int J Syst Bacteriol 38, 56-62.
Rainey, F. A., Toalster, R. \& Stackebrandt, E. (1993). Desufurella acetivorans, a thermophilic, acetate-oxidizing and sulfur-reducing organism, represents a distinct lineage within the Proteobacteria. Syst Appl Microbiol 16, 373-379.

Relman, D. A., Schmidt, T. M., MacDermott, R. P. \& Falkow, S. (1992). Identification of the uncultured bacillus of Whipple's disease. N Engl J Med 327, 293-301.

Saitou, N. \& Nei, M. (1987). The neighbour-joining method: a new method for reconstructing phylogenetic trees. Mol Biol Evol 4, 406-425.

Schoedon, G., Goldenberger, D., Forrer, R., Gunz, A., Dutly, F., Hochli, M., Altwegg, M. \& Schaffner, A. (1997). Deactivation of macrophages with IL-4 is the key to isolation of Tropheryma whippelii. J Infect Dis 176, 672-677.

Sebald, M. \& Veron, M. (1963). Teneur en bases de l'ADN et classification des vibrions. Ann Inst Pasteur 105, 897-910.

Skirrow, M. B. (1994). Diseases due to Campylobacter, Helicobacter and related bacteria. J Comp Pathol 111, 113-149.

Solnick, J. V., O'Rourke, J., Lee, A., Paster, B. J., Dewhirst, F. E. \& Tompkins, L. S. (1993). An uncultured gastric spiral organism is a newly identified Helicobacter in humans. I Infect Dis 168, 379-385.

Steele, T. W. \& McDermott, S. N. (1984). The use of membrane filters applied directly to the surface of agar plates for the isolation of Campylobacter jejuni from faeces. Pathology 16, 263-265.

Tanner, A. C. R., Badger, S., Lai, C. H., Listgarten, M. A., Visconti, R. A. \& Socransky, S. S. (1981). Wolinella gen. nov., Wolinella succinogenes (Vibrio succinogenes Wolin et al.) comb. nov., and description of Bacteroides gracilis sp. nov., Wolinella recta sp. nov., Campylobacter concisus sp. nov., and Eikenella corrodens from humans with periodontal disease. Int J Syst Bacteriol 31, $432-435$.

Tauxe, R. V. (1992). Epidemiology of Campylobacter jejuni infections in the United States and other industrialized nations. In Campylobacter jejuni: Current Status and Future Trends, pp. 9-19. Edited by I. Nachamkin, M. J. Blaser \& L. S. Tompkins. Washington, DC: American Society for Microbiology.

Thompson, L. M., III, Smibert, R. M., Johnson, J. L. \& Krieg, N. R. (1988). Phyogenetic study of the genus Campylobacter. Int J Syst Bacteriol 38, 190-200.

Vandamme, P., Falsen, E., Rossau, R., Hoste, B., Segers, P., Tytgat, R. \& De Ley, J. (1991). Revision of Campylobacter, Helicobacter, and Wolinella taxonomy: emendation of generic descriptions and proposal of Arcobacter gen. nov. Int J Syst Bacteriol 41, 88-103.

Van de Peer, Y. \& De Wachter, R. (1993). TREECON: a software package for the constuction and drawing of evolutionary trees. Comput Appl Biosci 9, 177-182.

Wilson, M. J., Weightman, A. J. \& Wade, W. G. (1997). Applications of molecular ecology in the characterization of uncultured microorganisms associated with human disease. Rev Med Microbiol 8, 91-101.

Woese, C. R. (1987). Bacterial evolution. Microbiol Rev 51, 221-271.

Received 10 December 1997; revised 6 April 1998; accepted 17 April 1998. 